\title{
Skala Gangguan Tidur untuk Anak [SDSC] sebagai Instrumen Skrining Gangguan Tìdur pada Anak Sekolah Lanjutan Tingkat Pertama
}

\author{
Christine Natalita, Rini Sekartini, Hardiono Poesponegoro \\ Departemen Ilmu Kesehatan Anak, Fakultas Kedokteran Universitas Indonesia - Rumah Sakit Cipto \\ Mangunkusumo
}

\begin{abstract}
Latar belakang. Dampak gangguan tidur pada remaja adalah penurunan prestasi akademis di sekolah, meningkatkan kenakalan remaja dan meningkatkan angka pemakaian rokok. Deteksi dini gangguan tidur perlu dilakukan karena remaja jarang mengeluh dan mengganggapnya bukan suatu masalah yang serius. Pemeriksaan gangguan tidur menggunakan polysomnography mahal dan tidak praktis, sedangkan pemeriksaan wrist actigraphy sederhana tetapi belum tersedia di Indonesia. Skala gangguan tidur untuk anak atau sleep disturbance scale for children (SDSC) praktis dan murah.

Tujuan. Mengetahui sensitivitas dan spesifisitas SDSC terhadap pemeriksaan wrist actigraphy.

Metode. Penelitian uji diagnostik dengan desain potong lintang selama bulan Juli-Oktober 2010. Murid yang memenuhi kriteria inklusi, dilakukan pemeriksaan wrist actigraphy dan pengisian kuisioner SDSC bersama orangtua.

Hasil. Sebagian besar subjek berusia 14 tahun (50\%). Rerata waktu subjek tidur adalah pukul 22:12, waktu subjek bangun pukul 05:55, dan total waktu tidur subjek 6 jam 47 menit. Terdapat 40 subjek (62,5\%) yang menderita gangguan tidur menurut SDSC dengan jenis gangguan yang paling sering adalah gangguan transisi tidur-bangun (25\%). Berdasarkan pemeriksaan wrist actigraphy terdapat 42 subjek (65,6\%) yang menderita gangguan tidur. Nilai diagnostik SDSC terhadap wrist actigraphy didapatkan sensitivitas 71,4\% dan spesifisitas $54,5 \%$. Nilai duga positif dan nilai duga negatif adalah $75 \%$ dan $50 \%$.

Kesimpulan. Sensitivitas dan spesifisitas SDSC terhadap pemeriksaan wrist actigraphy adalah 71,4\% dan $54,5 \%$. Instrumen SDSC dapat digunakan sebagai alat skrining gangguan tidur pada remaja.
\end{abstract}

Sari Pediatri 2011;12(6):365-72.

Kata kunci: gangguan tidur, wrist actigraphy, SDSC, remaja.

\footnotetext{
Alamat korespondensi:

Dr. Christine Natalita, Sp.A. Departemen Ilmu Kesehatan Anak FKUIRSCM Jl. Salemba no.6, Jakarta 10430. Telp. 087881650616/0213910096
}

Tidur merupakan komponen yang sangat penting bagi pertumbuhan fisis dan perkembangan intelektual anak. ${ }^{1}$ Hasil survei di Amerika menemukan lebih dari $20 \%$ tenaga kesehatan tidak melakukan secara rutin skrining gangguan tidur pada anak usia sekolah. ${ }^{2}$ 
Peneliti lain menemukan dokter anak jarang berdiskusi dengan orang tua mengenai masalah tidur pada anak. $^{3}$

Pola tidur berkembang sesuai dengan usia. Bayi baru lahir akan tidur hampir sepanjang waktu, tetapi setelah usia 6 bulan bayi tidur sekitar 13 jam per hari. Anak usia 2 tahun memerlukan tidur 12 jam termasuk tidur siang, usia 4 tahun selama 10-12 jam, dan usia remaja sekitar 9 jam per hari. ${ }^{4}$ Pada hari sekolah umumnya remaja memiliki waktu tidur lebih pendek sekitar 7,3 jam per hari. ${ }^{5}$ Pola tidur remaja memiliki ciri khas yang unik karena remaja mengalami perubahan hormonal dan pergeseran irama sirkadian. Remaja mulai merasa mengantuk pada tengah malam, sedangkan mereka harus bangun pagi hari untuk berangkat ke sekolah sehingga setiap hari mereka mengalami kekurangan waktu tidur.

Dampak kekurangan tidur pada remaja adalah meningkatkan angka ketidakhadiran di kelas, mempengaruhi prestasi di sekolah, meningkatkan penggunaan alkohol dan rokok, meningkatkan risiko obesitas, dan menurunkan daya tahan tubuh. ${ }^{6}$

Penelitian yang dilakukan oleh Chung $\mathrm{dkk}^{5}$ menemukan remaja dengan nilai akademik yang baik memiliki waktu tidur yang lebih awal dan jarang mengalami rasa mengantuk yang berat pada siang hari dibandingkan remaja yang memiliki nilai akademik yang rendah.

Gangguan tidur adalah kumpulan gejala yang ditandai oleh gangguan dalam jumlah, kualitas dan waktu tidur pada seseorang. ${ }^{7}$ Gangguan tidur pada anak sekolah ditemukan sekitar $46 \%$ dengan tipe gangguan yang paling sering adalah gangguan memulai dan mempertahankan tidur. ${ }^{8}$

Berdasarkan penelitian yang dilakukan oleh Haryono $\mathrm{dkk}^{9}$ terhadap anak usia 12-15 tahun di Sekolah Lanjutan Tingkat Pertama (SLTP) di Jakarta Timur menggunakan skala gangguan tidur pada anak/ sleep disturbance scale for children (SDSC) menyatakan prevalensi gangguan tidur pada anak usia 12-15 tahun adalah $62,9 \%$. Baku emas alat untuk mendiagnosis gangguan tidur adalah polysomnography (PSG). Alat ini memiliki kekurangan karena mahal, memerlukan rawat inap, dan tenaga ahli untuk menginterpretasikan hasilnya.

Alternatif alat untuk mendiagnosis gangguan tidur adalah wrist actigraphy. Alat tersebut mudah digunakan karena berbentuk seperti jam tangan dan hasil parameter tidur dianalisis menggunakan actiware software sehingga tidak memerlukan tenaga ahli.

Wrist actigraphy memiliki sensitivitas yang tinggi untuk merekam pergerakan waktu tidur $91,9 \%$ tetapi memiliki spesifisitas yang kurang baik untuk merekam status tidur $61 \%$. Rerata kesepakatan wrist actigraphy dengan PSG hanya $72,9 \% .{ }^{10}$ Keterbatasan penggunaan PSG menyebabkan American Academy of Sleep Medicine $(\mathrm{AASM})^{11}$ menetapkan wrist actigraphy sebagai alternatif alat diagnostik gangguan tidur. Tenaga kesehatan khususnya di daerah memiliki keterbatasan menggunakan PSG, sedangkan wrist actigraphy belum tersedia di Indonesia. Hal ini menginsyaratkan suatu instrumen yang murah, mudah, dan efektif dalam mendeteksi gangguan tidur pada remaja diperlukan.

Skala gangguan tidur pada anak (SDSC) merupakan kuisioner yang mudah diisi oleh orangtua bersama anak, dapat mendeteksi gangguan tidur dan jenis gangguan tidur yang sering dialami oleh anak, dan telah divalidasi dalam bahasa Indonesia. Kelemahan kuisioner ini adalah belum divalidasi secara obyektif sebagai alat ukur.

Penelitian dilakukan untuk mengetahui sensitivitas dan spesifisitas SDSC terhadap wrist actigraphy supaya SDSC dapat digunakan sebagai alat skrining yang akurat untuk mendeteksi gangguan tidur pada remaja. Pemilihan baku emas menggunakan wrist actigraphy bukan PSG karena alat ini sederhana, praktis, dapat dilakukan di rumah, dan tidak memerlukan tenaga ahli untuk menginterpretasikan hasilnya.

\section{Metode}

Penelitian dengan desain potong lintang dilakukan pada bulan Juni - Oktober 2010 terhadap pelajar SLTP "Galatia", Harapan Indah, Bekasi. Subjek penelitian pelajar berusia 12-15 tahun yang tersaring melalui kriteria inklusi dan eksklusi. Pemilihan subjek dilakukan dengan cara consecutive sampling.

Kuisioner diisi oleh pelajar bersama orangtua masing-masing di rumah. Alat wrist actigraphy akan dipasangkan pada lengan subjek seperti memakai jam tangan. Pemasangan dilakukan di rumah pelajar mulai dari pukul 20:00 sampai subjek bangun di pagi hari.

Wrist actigraphy mengukur sleep onset latency, efektifitas tidur, dan wake after sleep onset (WASO). Sleep onset latency adalah periode antara waktu subjek naik tempat tidur untuk tidur tanpa melakukan aktivitas lain dengan waktu subjek mulai tidur 
sebenarnya yang dinilai oleh actiware software. Subjek dikategorikan menderita gangguan tidur bila memiliki sleep onset latency $>20$ menit. Efektifitas tidur adalah persentase tidur dari interval istirahat subjek. Efektifitas tidur dihitung dengan membagi total waktu tidur subjek dengan jumlah menit pada keadaan istirahat subjek. Subjek dikategorikan mengalami gangguan tidur bila efektifitas tidurnya $<85 \%$. Wake after sleep onset jumlah menit dari keadaan bangun yang dideteksi oleh actiware softare sesudah subjek mulai tertidur. Subjek dikategorikan menderita gangguan tidur bila memiliki WASO >40 menit.

Penilaian gangguan tidur dilakukan dengan menggunakan kuisioner SDSC yang telah dimodifikasi berupa terjemahan ke dalam bahasa Indonesia yang sudah divalidasi dan dinilai realibilitasnya. Analisis pola tidur anak dilakukan dengan melakukan pemeriksaan wrist actigraphy. Data yang terkumpul dilakukan editing dan coding menggunakan program SPSS 17.0.

\section{Hasil}

Pengumpulan 193 formulir informed consent hanya 65 orangtua pelajar yang dapat dihubungi dan bersedia ikut serta dalam penelitian. Satu subjek yang dikeluarkan karena melepas alat wrist actigraphy sebelum waktunya. Terdapat 13 formulir yang ditandatangani penolakan oleh orangtua dan 21 formulir tanpa ditandatangani oleh orangtua. Distribusi data karakteristik subjek penelitian tertera pada Tabel 1 .

Berdasarkan hasil pengisian kuesioner SDSC didapatkan $62,5 \%$ subjek yang mengalami gangguan tidur yaitu subjek dengan skor SDSC lebih dari 39. Jenis gangguan tidur yang paling banyak ditemukan adalah gangguan transisi tidur-bangun (25\%). Sebaran subjek berdasarkan klasifikasi gangguan tidur tertera pada Tabel 2.

Berdasarkan pemeriksaan wrist actigraphy didapatkan rerata waktu subjek tidur adalah pukul 22:12, waktu bangun pukul 05:55, sehingga total waktu tidur 6 jam 47 menit. Hasil pemeriksaan wrist actigraphy dapat dilihat pada Tabel 3 .

Berdasarkan kriteria gangguan tidur menurut pemeriksaan wrist actigraphy, terdapat $22(34,4 \%)$ subjek yang memiliki efektifitas tidur kurang dari $85 \%, 10$ subjek (15,6\%) memiliki sleep onset latency lebih dari 20 menit dan WASO lebih dari 40 menit sebanyak 36 orang $(45,3 \%)$. Terdapat 42 subjek $(65,6 \%)$ yang memenuhi kriteria menderita gangguan tidur berdasarkan pemeriksaan wrist actigraphy yaitu subjek yang memiliki efektivitas tidur $<85 \%$, dan atau sleep onset latency $<20$ menit, dan atau WASO $>40$ menit.

Tabel 1. Sebaran subjek menurut karakteristik demografi $(\mathrm{n}=64)$

\begin{tabular}{lc}
\hline Karakteristik & $\mathrm{n}(\%)$ \\
\hline Jenis kelamin & \\
Perempuan & $32(50)$ \\
Laki-laki & $32(50)$ \\
Kelompok usia (tahun) & \\
Usia 12 & $10(15,6)$ \\
Usia 13 & $18(28,1)$ \\
Usia 14 & $32(50)$ \\
Usia 15 & $4(6,3)$ \\
Kegiatan ekstrakurikuler & \\
Ya & $25(39,1)$ \\
Tidak ada & $39(60,9)$ \\
Kebiasaan tidur siang & \\
Ya & $7(10,9)$ \\
Tidak & $57(89,1)$ \\
Memiliki TV/komputer di kamar tidur & \\
Ya & $12(18,8)$ \\
Tidak & $52(81,3)$ \\
Kebiasaan menjawab telepon genggam waktu & \\
jam tidur & \\
Ya & \\
Tidak & $6(9,4)$ \\
Teman tidur/co- sleeping & $58(90,6)$ \\
Ada & \\
Tidak ada & \\
\hline
\end{tabular}

Tabel 2. Sebaran subjek menurut skala gangguan tidur pada anak $(\mathrm{n}=64)$

\begin{tabular}{lc}
\hline Hasil SDSC & $\mathrm{n}(\%)$ \\
\hline Tidak mengalami gangguan tidur & $24(37,5)$ \\
Mengalami gangguan tidur & $40(62,5)$ \\
Gangguan memulai \& & $10(15,6)$ \\
$\quad$ mempertahankan tidur & \\
Gangguan pernafasan saat tidur & $3(4,7)$ \\
Gangguan kesadaran & $3(4,7)$ \\
Gangguan transisi tidur-bangun & $16(25)$ \\
Gangguan somnolen berlebihan & $8(12,5)$ \\
Hiperhidrosis saat tidur & $0(0)$ \\
\hline
\end{tabular}


Christine Natalita dkk: SDSC sebagai instrumen skrining gangguan tidur pada anak SLTP

Tabel 3. Pemeriksaan kualitas tidur menggunakan wrist actigraphy

\begin{tabular}{|c|c|c|c|c|c|c|c|}
\hline \multirow[t]{2}{*}{ Variabel } & \multirow[t]{2}{*}{ Rerata } & \multirow[t]{2}{*}{ SB } & \multicolumn{2}{|c|}{$95 \% \mathrm{CI}$} & \multirow[t]{2}{*}{ Median } & \multicolumn{2}{|c|}{ Rentang } \\
\hline & & & Low & High & & Min & $\operatorname{Max}$ \\
\hline Sleep onset latency(menit) & 13,5 & 7,6 & 11,7 & 15,4 & 12,0 & 2,0 & 34,0 \\
\hline Efektifitas tidur (\%) & 86,2 & 5,6 & 84,9 & 87,6 & 87,6 & 66,0 & 94,0 \\
\hline WASO (menit) & 45,3 & 21,5 & 40,1 & 50,6 & 44,5 & 8,0 & 105,0 \\
\hline
\end{tabular}

Tabel 4. Sebaran subjek menurut gangguan tidur berdasarkan pemeriksaan SDSC dan wrist actigraphy $(\mathrm{n}=64)$

\begin{tabular}{lcc}
\hline Gangguan tidur & Jumlah & Persen \\
\hline Gangguan menurut skor SDSC & & \\
Ya & 40 & 62,5 \\
Tidak & 24 & 37,5 \\
Gangguan menurut wrist actigraphy & & \\
Ada & 42 & 65,6 \\
$\quad$ Tidak ada & 22 & 34,4 \\
\hline
\end{tabular}

Tabel 5. Hubungan antara skor SDSC dan wrist actigraphy dalam penentuan gangguan tidur $(\mathrm{n}=64)$

\begin{tabular}{lccc}
\hline \multirow{2}{*}{$\begin{array}{l}\text { Menurut total skor } \\
\text { SDSC }\end{array}$} & \multicolumn{2}{c}{ Wrist actigraphy } & \multirow{2}{*}{ Jumlah } \\
\cline { 2 - 3 } & Pos & Neg & \\
\hline Ada gangguan & 30 & 10 & 40 \\
Tak ada gangguan & 12 & 12 & 24 \\
\hline Total & 42 & 22 & 64 \\
\hline Sensitivitas $=71,4 \%$ & & & \\
Spesifisitas $=54,5 \%$ & & & \\
Prediktif positif $=75,0 \%$ & & & \\
Prediktif negatif $=50,0 \%$ & & &
\end{tabular}

Didapatkan kesesuaian prevalensi gangguan tidur menurut skor SDSC dan menurut pemeriksaan wrist actigraphy tertera pada Tabel 4.

Hasil uji diagnostik antara SDSC dan wrist actigraphy dapat dilihat pada Tabel 5. Sensitivitas dan spesifisitas SDSC terhadap wrist actigraphy adalah 71,4\% dan $54,5 \%$. Nilai probabilitas seseorang menderita gangguan tidur dan tidak menderita gangguan tidur yang dibuktikan dengan wrist actigraphy, 75\% dan 50\%. Uji Mc Nemar untuk membandingkan hasil pemeriksaan SDSC dengan wrist actigraphy tidak didapatkan perbedaan (nilai $\mathrm{p}=0,832$ ), yang berarti kedua pemeriksaan ini sama.

\section{Pembahasan}

Berdasarkan hasil wawancara melalui telepon terdapat 11 orangtua menolak mengikutsertakan anaknya dalam penelitian ini. Alasan orangtua menolak adalah keyakinan orangtua bahwa anaknya tidak mengalami gangguan tidur, tidak mau direpotkan karena harus dilakukan wawancara dan pemeriksaan fisis ke rumahnya, dan merasa gangguan tidur bukan masalah serius. Pandangan tersebut sesuai dengan hasil survei yang dilakukan oleh Blunden $\mathrm{dkk}^{12}$ hanya terdapat $4,1 \%$ orangtua yang memiliki perhatian terhadap masalah ganguan tidur pada anak. Penyebab rendahnya pelaporan gangguan tidur pada anak karena orangtua kurang mengerti dampak gangguan tidur pada anak seperti penurunan nilai akademik, gangguan fungsi neurokognitif, dan peningkatan masalah kebiasaan mengantuk di siang hari.

Rerata waktu tidur subjek penelitian adalah pukul 22:12, waktu bangun pukul 05:55, dan total waktu tidur sebanyak 6 jam 47 menit. Hal ini hampir sama dengan yang ditemukan pada remaja di Jepang dan Korea. Rerata remaja di Jepang memiliki total waktu tidur sekitar 6,3 jam, waktu tidur pukul 00:03 dan waktu bangun pukul 06:33. Remaja di Korea memiliki total waktu tidur paling pendek yaitu hanya 5,4 jam dengan waktu tidur malam pukul 00:00. ${ }^{5}$

Terdapat 12 subjek $(18,7 \%)$ memiliki televisi atau komputer dalam kamar tidur dengan rerata menonton televisi atau bermain komputer dalam sehari sekitar 2,8 jam. Hal ini jauh lebih sedikit dari yang ditemukan oleh Shockat $\mathrm{dkk}^{13}$ pada tahun 2010, sekitar 60\% remaja memiliki televisi dan komputer di kamar tidur dengan 97,4\% memiliki akses internet. Dampak penggunaan media elektronik adalah memanjangnya sleep onset latency dan pengurangan total waktu tidur karena adanya pergantian waktu tidur dengan menonton televisi. ${ }^{14}$ Terdapat sekitar enam subjek $(9,4 \%)$ menggunakan telepon atau menjawab pesan melalui telepon genggam sewaktu jam tidur. Dampak melakukan aktivitas telepon genggam sewaktu jam tidur adalah meningkatkan kelelahan di siang hari sehingga mengganggu proses belajar di sekolah. ${ }^{15}$

Berdasarkan hasil kuisioner SDSC menggunakan total skor dengan $\mathrm{T}$ skor di atas persentil 55 dan jenis 
gangguan tidur dengan $\mathrm{T}$ skor diatas persentil 60. Terdapat 40 subjek $(62,5 \%)$ yang mengalami gangguan tidur dengan jenis gangguan transisi tidur bangun yang terbanyak dialami oleh subjek. Sesuai dengan hasil penelitian sebelumnya di SLTP Menteng, terdapat $62,9 \%$ murid yang memiliki gangguan tidur dengan gangguan transisi tidur bangun yang terbanyak. ${ }^{9}$

Prevalensi gangguan tidur menurut pemeriksaan wrist actigraphy berdasarkan kriteria efektivitas tidur < $85 \%$ dan atau sleep onset latency $>20$ menit dan atau WASO $>40$ menit $65,6 \%$, sesuai dengan prevalensi gangguan tidur berdasarkan SDSC.

Secara keseluruhan rerata subjek memiliki efektivitas tidur dan sleep onset latency yang cukup baik tetapi rerata WASO yaitu lamanya subjek terbangun saat tidur pada malam hari meningkat. Hal ini mungkin berkaitan dengan rerata subjek penelitian memiliki teman tidur/co-sleeping 51,6\%. Selain itu wrist actigraphy memiliki kelemahan tidak dapat membedakan pergerakan berasal dari subjek atau pengaruh dari luar.

Hasil uji penelitian kami mendapatkan kemampuan SDSC untuk mendeteksi gangguan tidur $71,4 \%$, kemampuan SDSC untuk menentukan subjek tidak menderita gangguan tidur $54,5 \%$, probabilitas subjek menderita gangguan tidur $75 \%$, probabilitas subjek tidak menderita gangguan tidur $50 \%$.

Hasil uji Mc Nemar didapatkan $\mathrm{p}=0,832$, artinya tidak terdapat perbedaan bermakna antara hasil SDSC dengan hasil wrist actigraphy. Maka SDSC dapat digunakan sebagai alat skrining gangguan tidur pada remaja. Disimpulkan sensitivitas dan spesifisitas SDSC terhadap wrist actigraphy $71,4 \%$ dan 54,5\%, perhitungan nilai duga positif dan negatif didapatkan $75 \%$ dan 50\%, prevalensi gangguan tidur menurut SDSC dan wrist actigraphy $62,5 \%$ dan 65,6\%. Jadi SDSC dapat digunakan sebagai alat skrining gangguan tidur pada remaja.

\section{Daftar pustaka}

1. Kieckhefer G, Ward T, Tsai D, Lentz M. Nighttime sleep and daytime nap pattern in school age children with and without asthma. J Dev Behav Pediatr 2008;29:33844.

2. Owen JA. The practice of pediatric sleep medicine: result of a community survey. Pediatrics 2001;108:e51.
3. Chervin RD, Archbold KH, Panahi P, Pituch KJ. Sleep problems seldom addressed at two general pediatric clinics. Pediatrics 2001;107:1375-80.

4. Dawson P. Sleep and sleep disorders in children and adolescents: information for parents and educators. Dalam: National Association of School Psychologists. Helping children at home and school II: handouts for families and educators. Bethesda: NASP; 2004.h.301-10.

5. Chung K, Cheung M. Sleep-wake patterns and sleep disturbance among Hong Kong Chinese adolescents. Sleep 2008;31:185-94.

6. Liu X, Uchiyama M, Okawa M, Kurita H. Prevalence and correlates of self reported sleep problems among Chinese adolescents. Sleep. 2010;23:27-34.

7. Hobson JA. Sleep disorder [diakses pada 24 Mei 2010]. Diunduh dari: http://www.answers.com/topic/sleepdisorder-2.

8. Bruni O, Ottaviano S, Guidetti V, Romoli M, Innocenzi M, Cortesi F, dkk. The sleep disturbance scale for children construction and validation of an instrumen to evaluate sleep disturbance in childhood and adolescent. J Sleep Res 1996;5:251-61.

9. Haryono A, Rindiarti A, Arianti A, Pawitri A, Ushuluddin A, Setiawati A, dkk. Prevalensi gangguan tidur pada remaja usia 12-15 tahun di Sekolah Lanjutan Tingkat Pertama. Sari Pediatri 2009;11:149-54.

10. Morgenthaler T, Alessi C, Friedman L, Owen J, Kapur V, Boehlecke B, dkk. Practice parameters for the use of actigraphy in the assessment of sleep and sleep disorders: an update for 2007. Sleep 2007;30:519-29.

11. Pollack C, Tryon W, Nagaraja H, Dzwonczyk R. How accurately does wrist actigraphy identify the states of sleep and wakefulness? Sleep 2001;24:957-65.

12. Blunden S, Lushington K, Lorenzen B, Ooi T, Fung F, Kennedy D. Are sleep problems under-recognised in general practice? Arch Dis Child 2004;89:708-12.

13. Schochat T, Flint-Bretler O, Tzizchinsky O. Sleep patterns, electronic media exposure and daytime sleeprelated behaviours among Israeli adolescents. Acta Paediatr 2010;99:1396-400.

14. Van den Bulck J. Television viewing, computer game playing, and internet use and self-reported time to bed and time out of bed in secondary-school children. Sleep 2004;27:101-4.

15. Van den Bulck J. Adolescent use of mobile phones for calling and for sending text message after lights out: results from a prospective cohort study with a one-year follow up. Sleep 2007;30:1220-3. 


\section{Kuesioner Penelitian}

Skala Gangguan Tidur pada Anak

(Sleeping Disturbance Scale for Children)

\section{Petunjuk:}

Kuesioner ini dapat membantu mengetahui pola tidur anak Bapak/Ibu dengan lebih baik. Selain itu, juga dapat mengetahui adanya gangguan tidur pada anak Bapak/Ibu.

Jawablah semua pertanyaan yang diajukan dengan mempertimbangkan kebiasaan tidur anak Bapak/Ibu dalam 6 bulan terakhir, saat anak Bapak/Ibu dalam keadaan sehat. Perubahan kebiasaan tidur karena anak sakit tidak termasuk. Jawablah dengan melingkari atau memberi tanda silang pada salah satu dari nomor $1-5$ yang dianggap mewakili kebiasaan tidur anak Bapak/Ibu.

Terima kasih atas partisipasi Bapak/Ibu.

\begin{tabular}{|l|c|c|c|c|c|}
\hline $\begin{array}{l}\text { 1. Berapa lama anak Bapak/Ibu } \\
\text { tidur pada malam hari? }\end{array}$ & $\begin{array}{c}(1) \\
9-11 \text { jam }\end{array}$ & $\begin{array}{c}(2) \\
8-9 \text { jam }\end{array}$ & $\begin{array}{c}(3) \\
7-8 \text { jam }\end{array}$ & $\begin{array}{c}(4) \\
5-7 \text { jam }\end{array}$ & $\begin{array}{c}\text { Kurang dari } 5 \\
\text { jam }\end{array}$ \\
\hline $\begin{array}{l}\text { 2.Berapa lama waktu yang } \\
\text { dibutuhkan anak Bapak/Ibu untuk } \\
\text { jatuh tidur sejak ia pergi ke tempat } \\
\text { tidur? }\end{array}$ & $\begin{array}{c}\text { Kurang dari } \\
15 \text { menit }\end{array}$ & $\begin{array}{c}(2) \\
15-30 \text { menit }\end{array}$ & $\begin{array}{c}(3) \\
30-45 \\
\text { menit }\end{array}$ & $\begin{array}{c}(4) \\
45-60 \text { menit }\end{array}$ & $\begin{array}{c}\text { Lebih dari } 60 \\
\text { menit }\end{array}$ \\
\hline
\end{tabular}

Pilihlah pernyataan berikut yang paling sesuai dengan kebiasaan tidur anak anda pada jam/waktu tidurnya. 


\begin{tabular}{|c|c|c|c|c|c|}
\hline & \multicolumn{5}{|c|}{5 Selalu (tiap hari) } \\
\hline \multicolumn{6}{|c|}{4 Sering (3-5 kali per minggu) } \\
\hline \multicolumn{6}{|c|}{3 Kadang-kadang (1-2 kali per minggu) } \\
\hline \multicolumn{6}{|c|}{2 Jarang (1-2 kali per bulan atau kurang) } \\
\hline 1 Tidak pernah & & & & & \\
\hline 3.Anak Bapak/lbu enggan atau menolak untuk tidur & 1 & 2 & 3 & 4 & 5 \\
\hline 4.Anak Bapak/lbu sulit untuk tidur pada malam hari & 1 & 2 & 3 & 4 & 5 \\
\hline 5.Ada rasa takut pada anak anda ketika mau tertidur & 1 & 2 & 3 & 4 & 5 \\
\hline 6. Bagian tubuh anak tampak tersentak ketika jatuh tertidur & 1 & 2 & 3 & 4 & 5 \\
\hline $\begin{array}{l}\text { 7. Anak melakukan gerakan berulang-ulang ketika jatuh tertidur } \\
\text { (seperti menggerakkan atau menggelengkan kepala) }\end{array}$ & 1 & 2 & 3 & 4 & 5 \\
\hline 8. Anak merasa mimpi seperti nyata ketika jatuh tertidur & 1 & 2 & 3 & 4 & 5 \\
\hline 9.Anak banyak berkeringat ketika jatuh tertidur & 1 & 2 & 3 & 4 & 5 \\
\hline 10. Anak terbangun dari tidur lebih dari 2 kali tiap malam & 1 & 2 & 3 & 4 & 5 \\
\hline $\begin{array}{l}\text { 11. Setelah terbangun pada malam hari, anak susah untuk tidur } \\
\text { kembali }\end{array}$ & 1 & 2 & 3 & 4 & 5 \\
\hline $\begin{array}{l}\text { 12. Kaki anak sering tersentak ketika tertidur atau sering berubah } \\
\text { posisi ketika malam atau sering menendang seprei tempat tidur }\end{array}$ & 1 & 2 & 3 & 4 & 5 \\
\hline 13. Anak mengalami kesulitan bernapas pada malam hari & 1 & 2 & 3 & 4 & 5 \\
\hline $\begin{array}{l}\text { 14. Anak sering terengah-engah saat bernapas atau tidak mampu } \\
\text { untuk bernapas ketika tidur }\end{array}$ & 1 & 2 & 3 & 4 & 5 \\
\hline 15. Anak mendengkur/mengorok ketika tidur & 1 & 2 & 3 & 4 & 5 \\
\hline 16. Anak berkeringat banyak pada malam hari & 1 & 2 & 3 & 4 & 5 \\
\hline 17. Bapak/lbu pernah menyaksikan anak berjalan dalam tidu & 1 & 2 & 3 & 4 & 5 \\
\hline
\end{tabular}




\begin{tabular}{|c|c|c|c|c|c|}
\hline 18. Bapak/Ibu pernah menyaksikan anak mengigau ketika sedang tidur & 1 & 2 & 3 & 4 & 5 \\
\hline $\begin{array}{l}\text { 19. Bapak/Ibu pernah mendengar gigi anak gemeretak/berbunyi ketika tidur } \\
\text { 20. Anak terbangun dari tidur dengan berteriak-teriak atau bingung, dan } \\
\text { susah untuk disadarkan, akan tetapi tidak bisa ingat ketika pagi harinya }\end{array}$ & 1 & 2 & 3 & 4 & 5 \\
\hline $\begin{array}{l}\text { 21.Anak mengalami mimpi buruk dan tidak bisa ingat kembali keesokan } \\
\text { harinya }\end{array}$ & 1 & 2 & 3 & 4 & 5 \\
\hline 22. Anak sangat sulit untuk bangun tidur & 1 & 2 & 3 & 4 & 5 \\
\hline 23. Anak bangun pada pagi hari dan merasa lelah & & & & & \\
\hline 24. Anak merasa tidak bisa untuk bergerak ketika bangun tidur pada pagi & 1 & 2 & 3 & 4 & 5 \\
\hline hari (ketindihan) & 1 & 2 & 3 & 4 & 5 \\
\hline 25. Anak merasa mengantuk pada siang hari & 1 & 2 & 3 & 4 & 5 \\
\hline $\begin{array}{l}\text { 26. Anak tiba-tiba jatuh tertidur pada situasi yang tidak seharusnya } \\
\text { (misalnya: ketika makan, berada dalam toilet, } \\
\text { dll) }\end{array}$ & 1 & 2 & 3 & 4 & 5 \\
\hline Gangguan memulai dan mempertahankan tidur (jumlah $1,2,3,4,5,10,11$ ) & 1 & 2 & 3 & 4 & 5 \\
\hline \multicolumn{6}{|l|}{ Gangguan pernapasan saat tidur (jumlah $13,14,15$ ) } \\
\hline \multicolumn{6}{|l|}{ Gangguan kesadaran (jumlah 17,20,21) } \\
\hline \multicolumn{6}{|l|}{ Gangguan transisi tidur-bangun (jumlah $6,7,8,12,18,19$ ) } \\
\hline \multicolumn{6}{|l|}{ Gangguan somnolen berlebihan (jumlah 22,23,24,25,26) } \\
\hline \multicolumn{6}{|l|}{ Hiperhidrosis saat tidur (jumlah 9,16) } \\
\hline SKOR TOTAL (jumlah 6 skor tiap faktor) & & & & & \\
\hline
\end{tabular}

